\title{
Automatic Promotion and Student Dropout: Evidence from Uganda, Using Propensity Score in Difference in Differences Model
}

\author{
Jeje Moses Okurut ${ }^{1}$ \\ ${ }^{1}$ Department of Regional Policy Cooperation Studies, Graduate School of International Cooperation Studies, \\ Kobe University, Japan \\ Correspondence: Jeje Moses Okurut, Department of Regional Policy Cooperation Studies, Graduate School of \\ International Cooperation Studies, Kobe University, Japan. E-mail: jejeokurut@gmail.com or \\ jeje.okmo@yahoo.co.uk
}

Received: November 27, 2017 Accepted: December 28, 2017 Online Published: January 16, 2018

doi:10.5539/jel.v7n2p191

URL: http://doi.org/10.5539/jel.v7n2p191

\begin{abstract}
The impact of automatic promotion practice on students dropping out of Uganda's primary education was assessed using propensity score in difference in differences analysis technique. The analysis strategy was instrumental in addressing the selection bias problem, as well as biases arising from common trends over time, and permanent latent differences between the treated and control groups. Probit regression results indicate a negative effect on the probability of students dropping out, but only at P3. There seems to be no policy effect at P6. Decomposing the effect incidence along school location shows the policy as having had an effect only on P3 students studying in urban schools; otherwise, there is no effect among students at P3 rural, P6 rural or P6 Urban. In terms of the gender component, automatic promotion appears to have had an effect on P3 male and female students and no effect on either sex at P6.
\end{abstract}

Keywords: automatic promotion; difference in differences; propensity score; student dropout

\section{Introduction}

Students' dropping out of school is one of the key indicators of the internal efficiency of an education system. It is an age-old phenomenon that continues to challenge, to varying degrees, efforts by governments and households to provide education to their citizens and household members respectively. Existing literature shows a lack of a standard definition and/ or understanding of student dropout, and as such different definitions are used at different times by different individuals/ institutions (see Lehr et al., 2004; Bonneau, 2015). According to Doll et al. (2013), the concept of student dropout has been documented from as early as the 1920s, where it was solely associated with students having mental inferiority. Thurlow et al. (2002) on their part note that student dropout can be defined through three dropout rates (1) event or annual or incidence rate; (2) status or prevalence rate, and; (3) cohort or longitudinal rate. The most common definition in use (including in Uganda) focuses on the first type of dropout rate. It states that a dropout is any student who leaves school for any reason before graduation or completion of a level of education/ program of studies, without transferring to another elementary or secondary school, mostly measured in annual terms (see also Bonneau, 2015). Moreover, the absence of an effective system to help governments and other education stakeholders track the movement of students in and out of an education system has led to inaccurate identification and calculation of student dropout rates (Lehr et al., 2004; Hoff et al., 2015; Sabates et al., 2010).

Since education is a public service, provided under a cost-sharing arrangement, involving the government and households, with governments covering tuition for all the students' enrolled, instructional materials, teachers' salaries, and households covering costs associated with school uniform, books, and pens, a high student dropout rate is a strong indicator of internal inefficiencies and wastage of resources (see Ndaruhutse, 2008; Abagi \& Odipo, 1997). Wastage to the government comes in the form of capitation grants paid for all the students enrolled, and tax revenue lost since more often than not students who drop out do not engage in productive and/ or income generating activities (see Mehrotra, 1998). Households incur losses in the form of money spent on instructional and scholastic materials required by the students. Learners who unfortunately drop out of school, face losses related to the time spent at given level of education (primary, secondary or tertiary) before exiting, as 
well as the potential income they could have earned after the completion of a schooling cycle (Eide \& Showalter, 2001).

Regarding causes of student dropout, grade retention has been identified as one of the strongest predictors (Almeda \& Mihiretieb, 2015; Chohan \& Qadir, 2011; King et al., 1999). In particular, grade retention is associated with increased expenditure for both governments and households, stigmatization of the affected students, low self-esteem, which more often than not lead to dropout (Myung et al., 2013; Manacorda, 2006; Glick \& Sahn, 2010). Given the overwhelming empirical evidence linking grade retention to student dropout, the opponents of grade retention have argued for it to be mitigated or eradicated. Consequently, education stakeholders in developing and developed countries have adopted and implemented different policy initiatives aimed at overcoming grade retention and dropout. One of the policy initiatives is automatic promotion (AP), also known as social promotion (Steiner, 1986). AP policy is strongly associated with holistic cognitive and non-cognitive development of the learners, since it eliminates grade retention and helps address the negative effects associated with it, including students dropping out (Ndaruhutse, 2008).

\subsection{AP and Student Dropout Rate in the Context of Uganda}

The AP policy was adopted and implemented in Uganda's primary education, in 2005 within the Universal Primary Education (UPE) framework. The overall objective was to foster the achievement of Education for All (EFA) goals and Millennium Development Goals (MDGs). AP was implemented as part of broader national education strategy aimed at enhancing internal efficiency under basic education. This is because by 2004 grade retention and dropout were recorded at approximately $35 \%$ and $21 \%$ respectively (see Okurut, 2015). Moreover, there were differences in inefficiency levels, along school location (rural or urban) and gender. In particular, repetition and dropout rates were higher among schools in rural areas and female students. According to EMIS database (2010), the dropout rate in 2004 was approximately $21 \%$, which by gender component was about $22 \%$ female and $20 \%$ male. By school location it was around $28 \%$ and $13 \%$ for students in rural and urban schools respectively. The above differences in dropout rates have been acknowledged and highlighted by Tamusuza (2011); and Okumu \& Nakajjo (2008).

Primary education in Uganda is comprised of seven grades, but AP is implemented only from Grade 1 to Grade 6. Grade 7 students have to sit and pass a nationally administered post-primary entrance exam called Primary Leaving Examination (PLE). Under AP framework, remedial classes are conducted during the course of the school term. The lessons are held early in the morning before normal classes begin and late in the evening after normal classes have ended, targeting academically weak students. Selective repetition is allowed, especially if a student for whatever reason (illness, domestic chores, household problems etc.) has missed many classes in the course of an academic year, and instances where some parents insist on their children repeating classes, if and when they are not satisfied with their children's performance in grade promotion exams.

\subsection{Statement of the Problem}

While the Ministry of Education, Science, Technology, and Sports (MoESTS) and donors have supported the implementation of AP, it has been mainly opposed by private providers, teachers, parents, school administrators and NGOs/CSOs. Both sides have actively used print and electronic media to express their arguments for or against AP, with neither side providing any evidence (see also Okurut, 2015).

Earlier studies on quality and internal efficiency of primary education in Uganda, including but not limited to Muvawala (2012); Ogawa et al. (2011); Tamusuza (2011); Byamugisha (2010); Kasirye (2009); Nishimura \& Ogawa (2009); Okumu et al. (2008); and Nannyonjo (2007) did not assess the impact of AP on student dropout. Okurut (2015) examined the impact of AP on students' learning achievements, but did not assess its impact on student dropout. Given the lack of evidence from either side, there is an information gap in the context of Uganda regarding the impact of AP on the rate at which students are dropping out of primary schooling, which this study sought to fill. Moreover, there is scant literature on AP and its impact from the point of Africa.The assessment captures the incidence of the treatment effect along two components i.e. students' gender and school location (rural or urban), in order to highlight the effectiveness of the policy to promote equity.

Internationally, multi-lateral education development agencies such as the World Bank, UNDP, UNICEF and UNESCO (see the World Development Reports, EFA Global Monitoring Reports and MDG Progress Reports) have highlighted the challenge of student dropout along gender and location, especially in Sub-Saharan Africa (SSA). They have subsequently called for measures/ strategies aimed at mitigating this problem. In addition, the SDG on education calls for all students (male and female) in rural and urban areas to successfully complete quality primary and secondary education by 2030 . This policy impact assessment is thus relevant to this 
discourse since it illustrates the effect of AP as one of the policy initiatives aimed at improving the internal efficiency of an education system.

\subsection{Objectives and Research Questions}

The main objective of this study is to assess the impact of implementing AP on students dropping out of primary schooling in Uganda. This objective is divided into two sub-objectives to enable the assessment of the effectiveness of AP in reducing student dropout in an equitable manner. The first sub-objective focuses on the effect of the policy on student dropout along school location (rural or urban). The second sub-objective looks at the impact of AP on student dropout along gender component. The overall research question was; what is the impact of AP practice on students dropping out of Uganda's primary education? The two sub-research questions are; (i) what is the effect of AP practice on students dropping out in rural and urban primary schools? (ii) what is the effect of AP practice on male and female students dropping out of primary schooling? These research questions shade light on the effectiveness of the AP policy, given that it was adopted to ensure that both male and female students stay in school, whether in rural or urban settings (Okurut, 2015). The rest of this paper is structured as follows: a review of previous studies, the methodology of the study, results and discussion, limitation of the study and policy implications.

\section{Review of Existing Literature}

\subsection{AP and Student Dropout}

This section illustrates some of the previous studies that have examined the impact of either AP or grade retention on the rate at which students are dropping out of school. The purpose is to provide evidence for or against the hypothesis of this study, which states that: AP has led to a decrease in the likelihood of students dropping out of primary education in Uganda. For instance, Ahmeda \& Mihiretieb (2015) and Taye (2003) both utilized qualitative method to examine the impact of the policy on students' dropout rate in early grades of primary schooling in Ethiopia. Specifically, Ahmeda \& Mihiretieb (2015) addressed the assertion that AP reduces school dropout in the context of primary education (Grades 1 to 3 ) in Ethiopia. They found that repetition puts students at risk of early dropout and that the policy is a viable response to grade retention. It reduces wastage since students get promoted and benefit from continuous support from the teachers, as well as studying with their peers. Taye (2003) on his part assessed the impact of AP policy in Ethiopia's primary education and found that $56.8 \%$ of the respondents believe grade repetition increases the likelihood that a student drops out.

The overall focus of the two studies is consistent with that of this study, with the difference being the methodological research approaches used. While this study employed a quantitative method, the two studies in Ethiopia both utilized qualitative method. Moreover, pronouncements by Ahmeda \& Mihiretieb (2015) and Taye (2003) are based only on the views and opinions of a few selected primary school administrators and teachers. Parents' and students' views/ opinions have not informed the findings of the two studies.

The effect of AP on student dropout was also assessed in Pakistan's primary education by King et al. (1999), and Chohan \& Qadir (2011). While Chohan \& Qadir (2011) employed qualitative research approach, King et al. (1999) employed quantitative research design. Chohan \& Qadir (2011) found that teachers consistently promoted students to save them from dropping out of the education system. This is because failing students increases the chances of them dropping out; whereas, if the students are continually promoted, their parents try to carry on supporting their children's education despite their economic hardships. King et al. (1999) on their part found that grade promotion raises the probability of a student continuing in primary school when that promotion is based on student performance, not when the promotion is uncorrelated with student achievement. It is worthy to note that findings by Chohan \& Qadir (2011) were based solely on the views and opinions of 42 sampled primary school teachers, implying that opinions/ views of school administrators, students and parents did not inform the findings and conclusions of the study.

In addition to the above scholars, Kopensteiner (2014) investigated the impact of automatic grade promotion on student dropout in grade 3 in Brazil; Glick \& Sahn (2010) analyzed the impact of grade retention and grade promotion on grade 2 student dropout in Senegal, and; Manacorda (2006) examined the effect of grade retention on primary school student dropout rate in Uruguay. More specifically, Koppensteiner (2014) employed quantitative approach and found AP to have actually been responsible for the reduction in dropout rates in 3rd Grade. By the same token, Glick \& Sahn (2010) found that retained students are more likely to leave school before completing primary school than students with similar ability, but not held back, pointing to the need for alternative measures to improve the skills of lagging children. Manacorda (2006) found that a large part of the disadvantage for grade failures manifests through immediate dropout. Compared to their non-retained colleagues, 
retained students are at disproportionate risk of abandoning school within one year after retention occurred. The study by Koppenstiener (2014) greatly informed my study in terms of policy under evaluation and the analysis technique. Data notwithstanding, empirical results by Glick \& Sahn (2010) give a relatively informative and comparative picture regarding the impact of grade retention on one hand and that of grade promotion on the other. This study and that conducted in Uruguay are different in that; whilst this study assessed the effect of AP on student dropout, the one in Uruguay focused on the impact of grade retention on student dropout. However, both studies acknowledge the detrimental effects of grade retention on the academic and social development of the learners.

The negative effect of grade retention was further emphasized by Myung et al. (2013) in a study conducted in the USA. The study investigated the effect of retention in grades 1 to 5 on reading and mathematics. They found that even if retention does not harm students academically or psychosocially, it may increase the likelihood of dropping out. This is because previously retained students reach the age for legally dropping out of school or working as well as other developmental milestones, such as becoming a parent, when they are further away from graduation than are continuously promoted same-age cohorts.

\subsection{AP and Student Dropout along Rural-Urban Dimension}

This segment of the report illustrates some of the earlier studies that have assessed the incidence of the effect of either AP or grade retention on dropout rate along school location (rural or urban) dimensions. The objective is to highlight evidence either for or against the sub-hypothesis that; AP has decreased the likelihood of students dropping out of rural and urban primary schools.

From Uganda, Tamusuza (2011); and Okumu \& Nakajjo (2008) explored the concept of student dropout from the point of view of rural-urban primary schooling. The two studies employed qualitative and quantitative research designs respectively. According to Tamusuza (2011), other things being equal, children in rural areas are more likely to drop out than children in urban areas, due to a number of factors, including grade retention. The hazard of dropping out of primary school is $60 \%$ higher in rural areas compared to urban areas. Similarly, Okumu \& Nakajjo (2008) noted that the probability of a child dropping out from primary school reduces as one moves from rural to urban areas. Student dropout in Uganda's primary education is a shared theme between this study and the two studies just highlighted above. It is worth pointing out that the two research studies (Tamusuza, 2011; and Okumu \& Nakajjo, 2008) did not assess the effect of AP on student dropout; rather they sought to identify the factors that can be attributed to student dropout. Both studies identified a number of factors, with grade retention as one of the leading causes of students dropping out of primary schooling.

In Brazil, Gomes-Neto \& Hanushek (1994) found that dropout rates increase across grades in rural areas compared to urban areas due to high-grade retention. The scholars used a unique panel data for students in northeast Brazil to analyze how the schooling system and individual students interact in determining enrollment patterns in primary schools. The effect of grade retention in the context of Brazilian primary schools was further analyzed by Vaidheesh (2013) who noted that retention affects students from poor rural and lower socioeconomic backgrounds more intensely than affluent students. Although findings from Brazilian primary education are substantiated by those from Uganda, not least because the research studies quoted from the two countries strongly acknowledge the undesired effect of grade retention on dropout, the impact of AP was not the centerpiece of their respective analyses.

Zarif et al. (2014) examined reasons explaining the high student dropout rate in grades 5 and 6, in the rural public schools of district Thatta, Sindh-Pakistan. The authors adopted a qualitative research design, where they sampled 30 schools from each Taluka of the district of Thatta. Findings indicate that many factors are associated with student dropout rate, some of which are school-level factors such as grade repetition, teachers' absenteeism, school location (rural or urban) and poor quality educational provision. However, despite the fact that Zarif used a closed-ended questionnaire during data collection exercise, the selection of respondents excluded school administrators and students, whose views and opinions are instrumental in assessing student dropout and its causes.

\subsection{AP and Student Dropout along Male-Female Divide}

Some of the earlier studies that investigated the incidence of the effect of either AP or grade retention on dropout along gender component i.e. male and female are illustrated under this section. The objective is to lend support or otherwise to the sub-hypothesis of the study, which states that; the practice of automatically promoting students has decreased the likelihood of male and female students dropping out of primary schools. 
In Pakistan, Chohan \& Qadir (2011); Lloyd et al. (2005); and Sawada \& Lokshin (2009) all analyzed student dropout based on gender component. According to Lloyd et al. (2005) both male and female students' dropout rates increased due to various reasons, including grade retention, as well as arrival in the family of an unwanted birth and enrollment in a government (not private) primary school. Non-grade retention, availability of post-primary schooling, having a mother who attended school and living in a better-off household reduce the probability of dropout. The authors noted that grade retention affects female students more than their male counterparts, thus leading to higher dropout rates among females. On the contrary, Chohan \& Qadir (2011) found that male student's dropout more than female students. The reasons for this include the fact that more male students are retained/ made to repeat grades than their female counterparts.

Sawada \& Lokshin (2009), examined the factors affecting secondary school dropout, with the objective of identifying obstacles to school progression using field surveys conducted in twenty-five Pakistani villages. They found a higher educational retention rate among females and subsequently higher dropout rates compared to the male students. Chohan \& Qadir (2011) and this study both assessed the impact of AP on student drop out at primary level, albeit using qualitative and quantitative methods respectively. Lloyd et al. (2005), and Sawada \& Lokshin (2009) did not assess the effect of AP and focused on factors affecting primary and secondary school dropout in Pakistan, using quantitative research design. Results from the three studies in Pakistan exhibit mixed patterns relative to the situation in Uganda's primary education.

In Cambodia, Hirakawa \& No (2012) conducted a longitudinal study on dropout and found that female students dropped out of school more than male students, and one of the factors explaining this gender bias was the relatively high retention rate among female students. This study was conducted in five primary schools and five lower secondary schools in rural parts of Kampong Cham province. Contrary to the results reported in Cambodia, Westbury (1994) found that male students are far more likely than their female counterparts to repeat an elementary school grade at a ratio of $60 \%$ to $40 \%$. This gender bias is a result of a higher tendency for male students repeating grades and teachers' invalid beliefs about children's physiological readiness for schooling which led to decisions to retain more of the slower maturing males. Results from Cambodia and Canada provide differing perspectives, with the situation in Cambodia more akin to the Ugandan one, contrasted with that of Canada. Both studies (in Cambodia and Canada) employed quantitative research method; however, they did investigate the impact of AP as the main focus.

From the USA, Anderson et al. (2003) investigated the effect of grade retention on achievement and health outcomes, focusing on elementary and high schools. They found that at the individual level many more boys are retained than girls and that because of this, coupled with poor academic achievement, low standardized test scores, absenteeism, and numerous school changes, retained students are likely to drop out. The tendency of male students being held back more than females, as reported by Anderson et al. (2003) is substantiated by Chohan \& Qadir (2011), but different from what is happening in Uganda's primary education. Moreover, whilst this study examined the effect of AP, Anderson et al. (2003) focused on the impact of grade retention.

\section{Empirical Methodology}

The effect of AP on students' dropout rate was estimated using propensity score in difference in differences (DID) technique, as proposed by Stuart et al. (2014) (Note 1). The two-stage strategy is justified because of its ability to address biases resulting from the selection of individuals, as well as from common trends over time, and from permanent latent differences between the treatment and control groups. While propensity score weighting strategy was instrumental in overcoming selection bias, DID model in parametric non-linear framework addressed bias from the other two sources mentioned above (Card \& Krueger, 1994; Abadie, 2005; Angrist \& Pischke, 2005). Moreover, the nature and structure of the dataset (pooled cross-section) used, favored this analysis technique. The method essentially involved using a weighted DID regression model as reflected in Equation (1).

$$
\begin{aligned}
& \operatorname{Pr}\left[Y_{i t}=1 \mid S_{i}, T_{t}, \delta, \varphi, \mu, \pi, \rho\right]=\beta_{0}+\beta_{1} S_{i}+\beta_{2} T_{t}+\beta_{3}\left(S_{i} * T_{t}\right)+\beta_{4} \delta+ \\
& \beta_{5} \varphi+\beta_{6} \mu+\beta_{7} \pi+\beta_{8} \rho+\varepsilon_{i t}
\end{aligned}
$$

Such that the outcome variable is represented by $\boldsymbol{Y}_{i t}$, and treatment status and time period are represented by parameters $\boldsymbol{S}_{\boldsymbol{i}}$ and $\boldsymbol{T}_{\boldsymbol{t}}$ respectively. The parameter $\left(\boldsymbol{S}_{\boldsymbol{i}} * \boldsymbol{T}_{t}\right)$ is the interaction term i.e., a product of treated group and post-treatment period. The Greek small letter DELTA $(\boldsymbol{\delta})$ represent school factors; the Greek small letter PHI 
( $\varphi$ ) represent regional dummies; the Greek small letter $M U(\boldsymbol{\mu})$ represent teacher explanatory variables; the Greek small letter $P I(\pi)$ represent student factors, and; the Greek small letter $R H O(\rho)$ represent household explanatory variables.

Essentially, DID framework requires two groups (treated and control), at least two time periods (before and after) and an outcome variable of interest (Card \& Krueger, 1994; Ashenfelter \& Card, 1985; Hastings, 2004). In the context of this study, the treatment is AP (implemented only by government schools). The before and after time periods are represented by the years 2004 and 2010. The two groups in this study are indexed by treatment status $(\boldsymbol{S}=\mathbf{1 , 0})$, whereby $\boldsymbol{S}=\mathbf{1}$ indicates students who received treatment (those in government schools) and $\boldsymbol{S}=\mathbf{0}$ indicates students who did not receive the treatment (those in private schools). The outcome variable, student dropout is a dichotomous variable ( 1 or 0 ) denoted by $\boldsymbol{Y}$, so that $\boldsymbol{Y}=\mathbf{1}$ if dropout was reported at each of the two grades under focus (Primary $3 \&$ Primary 6), at the time of data collection and $\boldsymbol{Y}=\boldsymbol{0}$ otherwise. The outcome variable is observed over two time periods $(\boldsymbol{T}=1,0)$ where $\boldsymbol{T}=\mathbf{1}$ indicates a time period after the treated group received treatment and $\boldsymbol{T}=\boldsymbol{0}$ indicates a time period before the treated group received treatment (Okurut, 2015).

The unit of analysis is student level such that the treated and control groups are comprised of students in government and private schools respectively. The decision to use students as the unit of analysis instead of schools was taken because ultimately the policy is geared towards ensuring that students stay in the primary schooling cycle to gain knowledge and skills required for their academic and personal development (Okurut, 2015). It is the students who are taught and assessed, who repeat classes and who drop out of the schooling cycle, so evaluating policy effect at this level is critical for designing and implementing comprehensive strategies for reducing dropout. This line of analysis is further justified by the fact that international commitments on education (SDGs, formerly EFA Goals and MDGs), whose achievement the policy is meant to enhance, target learners (male \& female) whether in rural or urban settings for purposes of promoting equitable and sustainable socio-economic development (Okurut, 2015).

The weighting strategy involved weighing the four DID groups namely; pre-treatment, post-treatment, pre-control and post-control, so that they are fairly similar on a set of characteristics contained in the dataset used. This removed biases resulting from differences in covariate distribution between the four groups. Propensity scores were estimated using a multinomial logistic regression predicting Group as a function of a set of observed $\mathrm{X}$ covariates. Consequently, each individual observation had four propensity scores, $\mathrm{z}_{\mathrm{m}}\left(\mathrm{X}_{\mathrm{i}}\right)$ i.e. the probability of being in Group $m$, for $m=1$ to 4 . The weights were then created using Equation (2), such that each of the four groups is weighted to Group 1, the treatment group in the pre-period (Stuart et al., 2014).

$$
v_{i}=z_{1}\left(X_{i}\right) / z_{g}\left(X_{i}\right)
$$

Whereby $g$ denotes a group to which individual $i$ belongs, implying that observations in Group 1 received a weight of 1 , while those in other groups received a weight that is proportional to the probability of them being in Group 1 relative to the probability of them being in their actual Group. Thus using the weights $V_{i}$ defined in equation (2), a reliable measure for every four parameters was derived with the help of Equation (3).

$$
\hat{\lambda}_{g}^{\prime}=\frac{\sum_{i=1}^{n} I\left(G_{i}=g\right) Y_{i} v_{i}}{\sum_{i=1}^{n} I\left(G_{i}=g\right) v_{i}}
$$

To infer causality it is imperative that the following assumptions governing this estimation method hold i.e., propensity score overlap, unconfoundedness, exogeneity and the parallel assumption (Stuart et al., 2014; Athey \& Imbens, 2006; Imbens \& Wooldridge, 2007). One of the limitations of the DID estimates relates to serial correlation, especially for studies that used time series or pooled cross sections datasets (Bertrand et al., 2004). In the same vein, propensity score method guarantees balance in only measured confounders, but not in unmeasured ones (Sainani, 2012). With the help of Breusch-Godfrey test, the presence of autocorrelation was investigated and found not to exist. However, it is plausible that the outcome of the test may have been influenced by the fact that only two time periods were used (Okurut, 2015).

\subsection{Assignment to Treatment}

The assignment was not done randomly, with the government simply announcing the adoption and implementation of the policy only in government/ public schools. The policy is therefore not implemented in private schools. The government's decision was inspired by the desire to; first of all cut financial costs, it incurs as a result of students repeating and secondly to reduce wastage of money for households, as a result of students dropping out of school. Under the UPE program, the government pays tuition in the form of capitation grants for all the students enrolled and as such cases of student repetition and dropout imply financial burden/ loss to the 
government as well as households. This is a major challenge, especially given the fact that in Uganda, there are more government/ public primary schools compared to private ones (12 203 out of 18 079), implementing UPE.

Given the fact that assignment to treatment status was not random, the existence of differences between the treatment and control group is recognized and acknowledged. The challenge then was to investigate the magnitude and stability or otherwise of the differences between the two groups, over time. Analysis results from the t-test for the equality of means between the two groups over the two time periods indicate very minimal differences. Table 1 and Table 2 (see Appendix) illustrate an overall similarity of summary statistics across treated and control groups based on school, teacher, student and household covariates for P3 and P6 respectively. In addition to the $\mathrm{t}$-statistic, the normalized differences between means by treatment status as a scale-free measure of the balancing properties for the covariates were computed using equation 4.

$$
\text { norm }-\operatorname{diff}=\frac{\overline{X_{0}}-\overline{X_{1}}}{\sqrt{S_{X_{0}}^{2}+S_{X_{1}}^{2}}}
$$

Where $\overline{X_{0}}$ and $\overline{X_{1}}$ are respectively the mean values of control and treated groups. $S_{X_{0}}^{2}$ and $S_{X_{1}}^{2}$ are the sample variances for control and treated groups respectively.

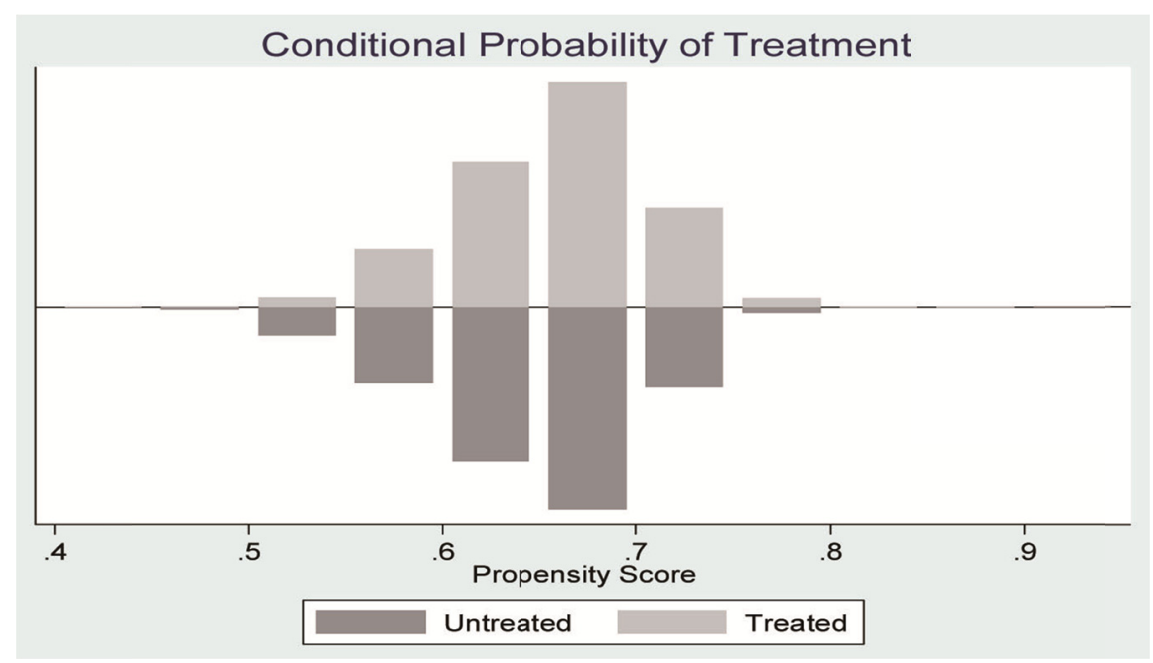

Figure 1. Histogram of the propensity score (2004)-P3

From Table 1 and Table 2 (see Appendix), it is evident that the values of respective covariate normalized differences are small and less than the standard absolute value of 0.25 (see Imbens \& Wooldridge, 2007; Koppensteiner, 2014). Moreover, the overlap and common support analysis was undertaken using propensity score, and the results are shown in Figure 1 and Figure 2. There is common support and overlap in the multivariate distribution of variables and a relatively uniform distribution of the propensity score for the treated and control groups. Common support and overlap conditions were assessed for purposes of ensuring that existing combinations of observed characteristics across the two groups are identical (see Bryson et al., 2002; Caliendo \& Kopeinig, 2005). Figure 2, shows that some observations do not fall within the common support region, however their number relative to the total number is small and as such treatment effect can plausibly be estimated and causality inferred (see Bryson et al., 2002; Caliendo \& Kopeinig, 2005). 


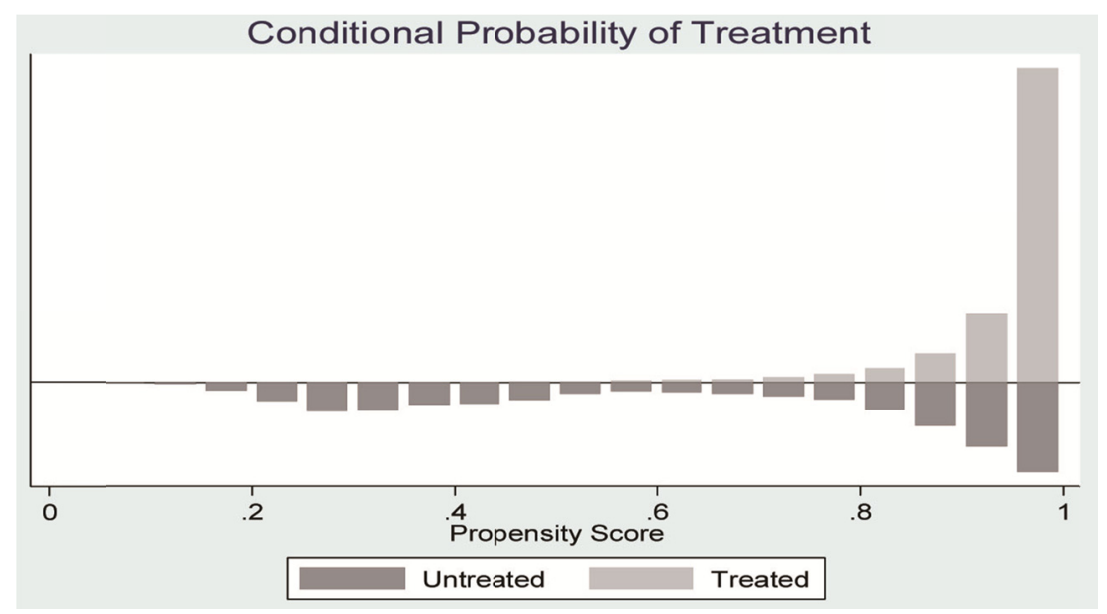

Figure 2. Histogram for the propensity score (2004) - P6

\subsection{Data Description}

The data utilized during this policy impact assessment comes from two sources i.e. MoESTS and Uganda Bureau of Statistics (UBOS). The first segment of the data is called National Assessment of Progress in Education (NAPE) and contains information related to schools characteristics, teachers' characteristics, student characteristics and regional dummies. NAPE data is collected annually by Uganda National Examinations Board (UNEB) from randomly selected government and private primary schools and is part of the Educational Management Information System (EMIS) database. Additional information contained in NAPE is that of student flow by grade, especially repetition, dropout, gender, and age. The dataset also contains learning achievements in language and mathematics, structured by district, school, and student.

The assessment is conducted in primary three (P3) and primary six (P6) in order to ascertain the level of students' learning achievement and to monitor changes in the achievement levels, as well as measuring the flow of students over time. Whilst P3 marks the end of lower primary, P6 though not the final grade of primary is selected to represent the end of upper primary, since primary seven (P7) students have to prepare for the national lower secondary entrance exam. The overall goal of NAPE is to assess the quality and efficiency of schooling at lower and upper levels of primary education (Okurut, 2015). The second installment of the data is the Uganda National Household Survey (UNHS) and provides household information including parents' education, household expenditure on education, distance from the household to the nearest primary school, number of children in a household and household social economic status. Descriptive statistics for school, teacher, student, and household related factors used during the analysis are illustrated in Table 1 and Table 2 (see Appendix).

\section{Results and Discussion}

\subsection{Effect of APon Students' Dropout Rate in Uganda's Primary Education.}

As an overview, it's worth noting that when computing and interpreting interaction terms for nonlinear models, the standard practice is not to stop at interpreting coefficients. This is because unlike in the linear regression case, where regression coefficients are the marginal effects, under non-linear regression, this is not the case. There is an additional step of computation required in order to get the marginal effects, after performing the usual non-linear regression. In the more recent versions of Stata, the second step involves using margins command to estimate the marginal effect at the means.

This line of analysis and interpreting the marginal effect of non-linear interaction terms is consistent with scholarly works by Ai \& Norton (2003); Phuni (2012); Zelner (2009); and Hoetker (2007). This study took into account computational and interpretation challenges associated with the marginal effect of interaction terms as highlighted by Williams (2012) and Bius (2010). On the basis of the above overview, before presenting the estimated impact (marginal effect) of the policy on the probability of students dropping out in the two grades under consideration, Table 3 shows a summary output of the first step of the analysis results for the effect of AP on student dropout rate at P3 and P6 after controlling for other selected variables (school, regional dummies, teacher, student and household). 
Table 3. Probit regression results of the effect of AP on students' dropout at P3 \& P6

\begin{tabular}{|c|c|c|c|c|c|c|}
\hline & \multicolumn{3}{|l|}{ P3 } & \multicolumn{3}{|l|}{ P6 } \\
\hline & $\begin{array}{l}\text { Coef. } \\
\text { (1) }\end{array}$ & $\begin{array}{l}\text { Robust Std. Err. } \\
\text { (2) }\end{array}$ & $\begin{array}{l}z \\
(3) \\
\end{array}$ & $\begin{array}{l}\text { Coef. } \\
(4)\end{array}$ & $\begin{array}{l}\text { Robust Std. Err. } \\
\text { (5) }\end{array}$ & $\begin{array}{l}z \\
(6) \\
\end{array}$ \\
\hline Post2005 & 1.100 & 0.142 & 7.72 & -0.138 & 0.055 & -2.49 \\
\hline Treatmentstatus & 0.488 & 0.107 & 4.56 & -0.032 & 0.061 & -0.53 \\
\hline Interactionterm & -0.598 & 0.128 & -4.67 & 0.039 & 0.067 & 0.59 \\
\hline Constant & 2.840 & 0.237 & 11.96 & 3.259 & 0.335 & 9.73 \\
\hline School Factors & Yes & & & Yes & & \\
\hline Regional Dummies & Yes & & & Yes & & \\
\hline Teacher Factors & Yes & & & Yes & & \\
\hline Student Factors & Yes & & & Yes & & \\
\hline Household Factors & Yes & & & Yes & & \\
\hline Observations & 30053 & & & 26720 & & \\
\hline Pseudo R2 & 0.085 & & & 0.067 & & \\
\hline
\end{tabular}

Note. Coef is the coefficient, Std. Err. is the standard error and $\mathrm{z}$ is the $\mathrm{z}$-statistic.

Table 4 illustrates the marginal effect of AP on the probability of students' dropping out at P3 and P6. The implementation of AP appears to have translated into approximately 7 percentage points decrease in the probability of students at lower primary (P3) dropping out as shown by the intersection between the interactionterm raw and columns 1 and $3(\mathrm{dy} / \mathrm{dx}=-0.074$ and $\mathrm{z}$-statistic $=-4.67)$. The negative marginal effect at P3 is interpreted as a reduction in the likelihood of a student dropping out, attributable to the implementation of the policy. At upper primary (P6), it appears the policy has not been effective, as reflected by the positive and statistically insignificant marginal effect, $\mathrm{dy} / \mathrm{dx}=0.004$ and z-statistic $=0.59$ (see the intersections between the interactionterm raw and columns 4 and 6 respectively). The information contained in Table 4 is in response to the main research question of the study, aimed at assessing the impact of AP on students' dropout rate in Uganda's primary education.

Table 4. Marginal effect of AP on the probability of students' dropping out at P3 and P6

\begin{tabular}{|c|c|c|c|c|c|c|c|c|}
\hline Independent Variables & $\begin{array}{l}\text { P3 } \\
d y / d x\end{array}$ & $\begin{array}{l}\text { Delta-method } \\
\text { Err. } \\
(2)\end{array}$ & Std. & $\begin{array}{l}\mathrm{z} \\
(3) \\
\end{array}$ & $\begin{array}{l}\text { P6 } \\
d y / d x\end{array}$ & $\begin{array}{l}\text { Delta-method } \\
\text { Err. } \\
(5)\end{array}$ & Std. & $\begin{array}{l}z \\
(6) \\
\end{array}$ \\
\hline Post2005 & 0.136 & 0.018 & & 7.69 & -0.017 & 0.007 & & -2.49 \\
\hline Treatmentstatus & 0.060 & 0.013 & & 4.55 & -0.004 & 0.008 & & -0.53 \\
\hline Interactionterm & -0.074 & 0.015 & & -4.67 & 0.004 & 0.008 & & 0.59 \\
\hline School Factors & Yes & & & & Yes & & & \\
\hline Regional Dummies & Yes & & & & Yes & & & \\
\hline Teacher Factors & Yes & & & & Yes & & & \\
\hline Student Factors & Yes & & & & Yes & & & \\
\hline Household Factors & Yes & & & & Yes & & & \\
\hline Observations & 30053 & & & & 26720 & & & \\
\hline
\end{tabular}

Note. dydx represents the marginal effect and $\mathrm{z}$ is the $\mathrm{z}$-statistic.

The findings at P3 are consistent with earlier scholars such Myung et al. (2013); Koppensteiner (2014); Froman \& Brown (2008); Jimmerson \& Ferguson (2007); Chohan \& Qadir (2011) who all found that grade retention increased dropout rate, especially among retained students. However, the findings are contrary to the popular belief in Uganda (reflected mostly in print and electronic media), which is that the policy does not reduce students' dropout rates, rather it increases it. Estimation results at P6 appear to be consistent with the general public opinion in Uganda about AP policy and contrary to several existing studies on the impact of the policy and grade retention.

In the Ugandan context, the effectiveness of the policy at P3 and its ineffectiveness at P6 can be explained by a number of reasons including but not limited to the fact that P6 students are viewed as much needed cheap/ free labour to help with domestic activities, implying that they more susceptible to being held back at home. The resulting irregular attendance disrupts students' involvement and participation in school and classroom activities, 
which more often than not leads to dropping out since it gives the learners a sense of not belonging in the school environment.

Moreover, most students do not have meals at school, despite the provisions under the UPE implementation guidelines. Lower primary students study only half day and as such go back home at mid-day (noon), and eat at home, while their upper primary colleagues have to stay in school for afternoon lessons, sometimes without anything to eat. The situation is further hampered by the fact that parents have not stepped up to play one of their roles of providing food (mid-day meal) for children to eat during schools days. According to the MoESTS, 2014, lack of school feeding continues to impede government's efforts towards reducing students' dropout rate, especially at upper primary which includes P6.

\subsubsection{Effect of AP on Students' Dropout Rate in Rural and Urban Primary Schools}

When the effect is decomposed along school location (rural-urban) dimension, estimation results show that the implementation of the policy seems to have been ineffective in reducing the probability of students dropping out in the two grades under review. Table 5 illustrates probit regression results and Table 6 illustrates the marginal effect of AP on the probability of students dropping out along rural-urban component. In particular, the policy seems to have had a positive effect on P3 students studying in urban school, which is statistically significant as can be seen in the points of intersection between the interactionterm raw and columns 3 and $4(\mathrm{dy} / \mathrm{dx}=0.071$ and z-statistic $=4.04$ ). This result is thus interpreted as an increase in the probability of P3 students in urban primary schools dropping out, by approximately 7 percentage points, attributed to the policy. By contrast, it appears AP has had no effect on students studying in rural schools, as can be seen by the value of the marginal effect at P3 rural (-0.056), which is not statistically significant as evidenced by the z-statistic $=-1.68$ (see the intersection between the interactionterm raw and columns 1 and 2).

Table 5. Probit regression results of the effect of APon students' dropout in rural \& urban areas - P3 \& P6

\begin{tabular}{|c|c|c|c|c|c|c|c|c|}
\hline \multirow[t]{3}{*}{ Variables } & \multicolumn{4}{|l|}{ P3 } & \multicolumn{4}{|l|}{ P6 } \\
\hline & Rural & & Urban & & Rural & & Urban & \\
\hline & $\begin{array}{l}\text { Coef. } \\
\text { (1) }\end{array}$ & $\begin{array}{l}\mathrm{z} \\
(2) \\
\end{array}$ & $\begin{array}{l}\text { Coef. } \\
\text { (3) }\end{array}$ & $\begin{array}{l}z \\
(4) \\
\end{array}$ & $\begin{array}{l}\text { Coef. } \\
(5)\end{array}$ & $\begin{array}{l}z \\
(6) \\
\end{array}$ & $\begin{array}{l}\text { Coef. } \\
\text { (7) }\end{array}$ & $\begin{array}{l}\mathrm{Z} \\
(8)\end{array}$ \\
\hline Post2005 & 0.374 & 1.53 & 0.354 & 2.96 & -0.147 & -2.20 & -0.112 & -1.14 \\
\hline Treatmentstatus & -0.147 & -0.64 & 0.124 & 1.28 & -0.044 & -0.59 & 0.017 & 0.16 \\
\hline Interactionterm & -0.427 & -1.68 & 0.675 & 4.03 & 0.010 & 0.13 & 0.097 & 0.80 \\
\hline Constant & 2.668 & 8.90 & 1.587 & 5.07 & 2.531 & 10.04 & 2.410 & 5.92 \\
\hline School Factors & Yes & & Yes & & Yes & & Yes & \\
\hline Regional Dummies & No & & No & & No & & No & \\
\hline Teacher Factors & Yes & & Yes & & Yes & & Yes & \\
\hline Student Factors & Yes & & Yes & & Yes & & Yes & \\
\hline Household Factors & Yes & & Yes & & Yes & & Yes & \\
\hline Observations & 20194 & & 9859 & & 19388 & & 7332 & \\
\hline Pseudo R2 & 0.083 & & 0.110 & & 0.072 & & 0.059 & \\
\hline
\end{tabular}

In addition, the policy appears to have had no effect, on the probability of students in P6 in rural and urban primary schools dropping out. The findings for students studying in schools located in rural areas are reflected by the points of intersection between the interactionterm raw and columns 5 and 6 , where the marginal effect for $\mathrm{P} 6$ rural is 0.001 and the z-statistic is 0.13 . The marginal effect for students studying in urban schools is 0.012 , not statistically significant with a z-statistic of 0.80 (see the interactionterm raw and Columns 7 and 8). The results in Table 6 are in response to the first sub-research question, which inquired about the existence of a causal relationship between AP and student dropout along rural-urban component, in the two grades. 
Table 6. Marginal effect of automatic promotion on the probability of students dropping out of schools located in rural and urban settings - P3 and P6

\begin{tabular}{|c|c|c|c|c|c|c|c|c|}
\hline \multirow[t]{2}{*}{ Independent Variables } & \multicolumn{4}{|l|}{ P3 } & \multicolumn{4}{|l|}{ P6 } \\
\hline & $\begin{array}{l}\text { Rural } \\
d y / d x \\
(1)\end{array}$ & $\begin{array}{l}z \\
(2) \\
\end{array}$ & $\begin{array}{l}\text { Urban } \\
\mathrm{dy} / \mathrm{dx} \\
(3) \\
\end{array}$ & $\begin{array}{l}\mathrm{z} \\
(4) \\
\end{array}$ & $\begin{array}{l}\text { Rural } \\
\mathrm{dy} / \mathrm{dx} \\
(5) \\
\end{array}$ & $\begin{array}{l}z \\
(6) \\
\end{array}$ & $\begin{array}{l}\text { Urban } \\
\text { dy/dx } \\
(7)\end{array}$ & $\begin{array}{l}\mathrm{Z} \\
(8) \\
\end{array}$ \\
\hline Post2005 & 0.049 & 1.53 & 0.037 & 2.95 & -0.018 & -2.20 & -0.014 & -1.14 \\
\hline Treatmentstatus & -0.019 & -0.64 & 0.013 & 1.28 & -0.005 & -0.59 & 0.002 & 0.16 \\
\hline Interactionterm & -0.056 & -1.68 & 0.071 & 4.04 & 0.001 & 0.13 & 0.012 & 0.80 \\
\hline School Factors & Yes & & Yes & & Yes & & Yes & \\
\hline Regional Dummies & No & & No & & No & & No & \\
\hline Teacher Factors & Yes & & Yes & & Yes & & Yes & \\
\hline Student Factors & Yes & & Yes & & Yes & & Yes & \\
\hline Household Factors & Yes & & Yes & & Yes & & Yes & \\
\hline Observations & 20194 & & 9859 & & 19388 & & 7332 & \\
\hline
\end{tabular}

Note. dydx represents the marginal effect and $\mathrm{z}$ is the $\mathrm{z}$-statistic.

These findings resonate with views and opinions of the opponents of the policy both nationally within Uganda and substantiated by several international scholars such as Brophy (2006) and Jimerson \& Ferguson (2007) who have reported increased student dropout as a result of implementing the policy, and as such are in support of grade retention. Conversely, these findings are contrary to earlier scholars who have attributed AP practice to the improvement of internal efficiency of an education system, especially after factoring rural-urban component (see Tamusuza, 2011; Ndaruhutse, 2008).

Possible reasons for these findings include; limited community and household participation in school activities, irregular support supervision of school administrators, negative attitudes towards education, especially among parents in rural areas, inadequate supply of teaching and learning materials, to mention but a few. In addition, and as already mentioned, students at upper primary (P6) are relatively older than their P3 colleagues and as such represent free additional labor for households, especially in rural areas. Consequently, P6 students more often than not get involved in domestic activities such as gardening, marketing, cooking and the like.

The MoESTS (2014) identifies long distances to schools as one of the reasons that make children drop out. This is especially true in rural areas where sparsely populated areas have schools that are $10 \mathrm{kms}$ or more away from some clusters that people live which discourages children from going to school. It is worth re-emphasizing that the policy works in complement with other factors that influence efficiency in education, so in situations where supplementary/complementary factors are not conducive, the effectiveness of the policy is greatly diminished and in some cases completely negated.

4.1.2 Effect of AP on the Rate at which Male and Female Students are Dropping out of Primary Schooling in Uganda

Regarding gender component, regression results reveal a negative effect on the likelihood of male and female students dropping out of school only at P3 (see Table 8). Table 7 depicts probit regression output for the effect of the policy on the students' dropout rate at P3 and P6, structured along gender component. From Table 8, two general observations can be made, the first being that the policy appears to have translated into a reduction in the likelihood of P3 students dropping out of primary schooling for both males and females. The second observation is that at P6 the policy seems to have had no effect on the probability of both male and female students dropping out of school. The intersection points between the interactionterm raw and Columns 1 and 2 show that the probability of male students at $\mathrm{P} 3$ dropping out decreased by approximately 7 percentage points, statistically significant at conventional levels $(z$-statistic $=-3.19)$. The marginal effect on P3 female students is shown by the intersection between the interactionterm raw and columns 3 and $4(\mathrm{dy} / \mathrm{dx}=-0.074$ percentage points and $z$-statistic $=-3.27$. 
Table 7. Probit regression results of the effect of AP on male and female students' dropout - P3 and P6

\begin{tabular}{|c|c|c|c|c|c|c|c|c|}
\hline \multirow[t]{4}{*}{ Independent Variables } & \multicolumn{4}{|l|}{ P3 } & \multicolumn{4}{|l|}{ P6 } \\
\hline & Male & & Female & & Male & & Female & \\
\hline & Coef. & $\mathrm{Z}$ & Coef. & $\mathrm{z}$ & Coef. & $\mathrm{z}$ & Coef. & $\mathrm{z}$ \\
\hline & $(1)$ & $(2)$ & (3) & $(4)$ & $(5)$ & (6) & $(7)$ & $(8)$ \\
\hline Post2005 & 1.132 & 5.47 & 1.052 & 5.32 & -0.052 & -0.85 & -0.716 & -4.12 \\
\hline Treatmentstatus & 0.473 & 3.06 & 0.475 & 3.21 & -0.032 & -0.50 & -0.172 & -0.87 \\
\hline Interactionterm & -0.585 & -3.20 & -0.586 & -3.27 & 0.083 & 1.09 & 0.132 & 0.65 \\
\hline Constant & 2.504 & 9.22 & 2.189 & 5.90 & 2.336 & 8.00 & 3.163 & 8.60 \\
\hline School Factors & Yes & & Yes & & Yes & & Yes & \\
\hline Regional Dummies & Yes & & Yes & & Yes & & Yes & \\
\hline Teacher Factors & Yes & & Yes & & Yes & & Yes & \\
\hline Student Factors & Yes & & Yes & & Yes & & Yes & \\
\hline Household Factors & Yes & & Yes & & Yes & & Yes & \\
\hline Observations & 15407 & & 14646 & & 15066 & & 11654 & \\
\hline Pseudo R2 & 0.084 & & 0.084 & & 0.056 & & 0.089 & \\
\hline
\end{tabular}

Note. Coef is the coefficient and $\mathrm{z}$ is the $\mathrm{z}$-statistic.

At P6, the intersections between Columns 5 and 6, and the interactionterm raw indicate that AP seems to have had no effect on the probability of male students dropping out of primary schooling (z-statistic $=1.09)$. Likewise, there appears to have been no effect on the probability of P6 female students dropping out, as demonstrated by the intersection between columns 7 and 8 , and the interactionterm raw. The findings in Table 8 are in response to the second sub-research question, geared towards investigating the impact of implementing the policy on dropout rates among male and female students. Regression results for P3 are consistent with previous studies (see Hirakawa \& No, 2012; Chapman, 2011; Jimerson et al., 1997) that have been conducted in less developed countries. The general trend among less developed countries is that girls not only dropout the most, but have the highest likelihood of dropping out of school, precisely because of the reasons already highlighted above. Estimation results for P6 are contrary to findings by earlier scholars such as Ndaruhutse (2008).

Table 8. Marginal effect of AP on the probability of male and female students dropping out - P3 and P6

\begin{tabular}{|c|c|c|c|c|c|c|c|c|}
\hline \multirow[t]{2}{*}{ Independent Variables } & \multicolumn{4}{|l|}{ P3 } & \multicolumn{4}{|l|}{ P6 } \\
\hline & $\begin{array}{l}\text { Male } \\
\mathrm{dy} / \mathrm{dx} \\
(1) \\
\end{array}$ & $\begin{array}{l}z \\
(2) \\
\end{array}$ & $\begin{array}{l}\text { Female } \\
\mathrm{dy} / \mathrm{dx} \\
(3)\end{array}$ & $\begin{array}{l}z \\
(4) \\
\end{array}$ & $\begin{array}{l}\text { Male } \\
d y / d x \\
(5) \\
\end{array}$ & $\begin{array}{l}z \\
(6) \\
\end{array}$ & $\begin{array}{l}\text { Female } \\
\mathrm{dy} / \mathrm{dx} \\
(7)\end{array}$ & $\begin{array}{l}z \\
(8) \\
\end{array}$ \\
\hline Post2005 & 0.138 & 5.44 & 0.133 & 5.30 & -0.006 & -0.85 & -0.087 & -4.11 \\
\hline Treatmentstatus & 0.057 & 3.05 & 0.060 & 3.21 & -0.004 & -0.50 & -0.021 & -0.87 \\
\hline Interactionterm & -0.071 & -3.19 & -0.074 & -3.27 & 0.010 & 1.09 & 0.016 & 0.65 \\
\hline School Factors & Yes & & Yes & & Yes & & Yes & \\
\hline Regional Dummies & Yes & & Yes & & Yes & & Yes & \\
\hline Teacher Factors & Yes & & Yes & & Yes & & Yes & \\
\hline Student Factors & Yes & & Yes & & Yes & & Yes & \\
\hline Household Factors & Yes & & Yes & & Yes & & Yes & \\
\hline Observations & 15407 & & 14646 & & 15066 & & 11654 & \\
\hline
\end{tabular}

Note. dydx represents the marginal effect and $\mathrm{z}$ is the $\mathrm{z}$-statistic.

The similarity in the effect among male and female learners at P3 implies that the policy is effective in terms of promoting gender equity in access and efficiency to schooling and continued enrolment. The findings at $\mathrm{P} 3$ are particularly encouraging in the struggle and advocacy for girls staying in school until they complete the primary cycle of education. However, the lack of policy effect along gender component at P6 raises serious concerns, especially regarding issues such as negative attitudes of the parents towards the education, lack of school requirements, early marriages, chronic illnesses, loss of a parent or guardian, lack of school feeding programs, long distances to and from schools, household/ domestic chores etc., all having the potential to undermine the effective implementation of the policy (MoESTS, 2014).

The situation in Uganda's primary education is such that students in upper grades of primary schooling are highly susceptible to drop out. In particular, female students drop out of school at a rate much higher than that of male students. Females tend to be withdrawn more for both economic and social-cultural reasons, which 
translates into the increase in the dropout. Therefore the advent of AP provided an opportunity for all the students to be promoted to the next grade, except in special cases such as sickness and missing many classes.

\section{Limitations of the Study}

Some of the limitations of the study, as well as possible ways through which they can be overcome in the future, are discussed here below. To begin with, the data used was not from an experimental research design, since the government simply announced the introduction of AP in public schools and not private schools (Okurut, 2015). However, even though randomization cannot be guaranteed, there are similarities between control and treated groups. The differences between the two groups are generally minimal and relatively stable over time, thus allowing for plausible causal inference (Murnane \& Willet, 2011; Morgan \& Winship, 2007; Antonakis et al., 2010).

Secondly, the issue of whether there is strict adherence to the implementation of the policy in all the government primary schools in the country was not addressed by this policy impact assessment. There is a very distinct possibility that some government or public primary schools are not implementing the policy, which greatly affects the composition and structure of the treatment group. Closely related to the above is the fact that this study did not address the movement of students from government schools to private schools and vice versa. This cross movement of learners between primary schools (treated and control) also influences the composition of the two groups. With enough time and resources, a well-designed study aimed at collecting data from the field (control and treatment schools) will be instrumental in tackling these challenges.

Lastly, the data utilized during the analysis was not gathered for purposes of evaluating the effect of AP policy in particular. This means that there are observed and unobserved variables missing from the dataset, that influence student dropout, meaning that the estimated effect of the policy justifiably attracts some critical reviews. Given enough time and resources, future assessment of the impact of AP in the context of Uganda should be based on data specifically geared towards this purpose.

\section{Policy Implications}

Based on the analysis and discussion of the results, a couple of policy observations applicable not only in Uganda, but also in developing countries, emerge. First and foremost, governments already implementing or planning to implement AP should carryout nationwide sensitization programs aimed at educating stakeholders about AP, why the government adopted it or is planning to implement it, as well as its strength and weaknesses. The sensitization drive should be a collaborative effort between the government and education development partners in the country. Drawing from the print and electronic media in Uganda, it is clear that to date there hasn't been any consultation and sensitization about the policy, especially why it is relevant to the efficient and effective provision and development of education in Uganda.

In addition, governments, especially in developing countries, should ensure adequate availability of complementary/ supplementary factors that influence the internal efficiency and quality of primary education. The fact that the policy appears to be effective at lower primary (P3) and not at upper primary (P6) in Uganda, reinforces the fact that different factors affect schooling patterns of students by age and grade. Since AP does not operate in isolation, age and grade level factors dictate the effectiveness of the policy one way or the other.

Furthermore, there is a need for governments to implement affirmative action strategies targeted at ensuring that all schools, including those located in rural areas are conducive for effective teaching and learning process. For instance, in Uganda, a national school feeding program needs to be launched to cover all schools, with special emphasis on rural schools. Moreover, construction of post-primary schools/ institutions and provision of solar power in rural areas will help attract and motivate learners and parents to invest in education. Post-primary institutions are pathways for progression through the education system, especially after graduating from primary level of education. Coupled with the above is the need to address the negative attitudes of parents in rural areas regarding the short and long-term benefits of investing in education. The policy implications discussed above are not only true and relevant in the case of implementing AP in Uganda's primary education, but internationally recognized and prescribed to countries grappling with the challenges of making the policy achieve the desired outcomes.

\section{Acknowledgements}

I'm highly indebted to my academic advisor Dr. Keiichi Ogawa (Professor) for his counsel and guidance during the entire process of writing this paper. I'm also grateful to Dr. Shinsaku Nomura for his detailed and insightful comments and guidance during the analysis stage. Lastly, I'm grateful to Mitsubishi Corporation for the 
International Students Scholarship for the financial support that enabled me to pursue my doctoral studies and conduct this research.

\section{References}

Abadie, A. (2005). Semi-parametric Difference-in-Differences Estimators. Harvard University and NBER. Review of Economic Studies, 72, 1-19. https://doi.org/10.1111/0034-6527.00321

Abagi, O., \& Odipo, G. (1997). Efficiency of primary education in Kenya: A situational analysis and implications for educational reform. Institute of Policy Analysis and Research. Discussion Paper No. DP 004/97, $\quad$ pp. $1-41 . \quad$ Retrieved from http://citeseerx.ist.psu.edu/viewdoc/download;jsessionid=3E3E8281D39403AC70FC479FC14AC1D2?doi= 10.1.1.626.4942\&rep=rep1\&type $=$ pdf

Ahmeda, A. Y., \& Mihiretieb, D. M. (2015). Primary school teachers and parents' views on automatic promotion practices and its implications for education quality. International Journal of education Development, 43, 90-99. http://dx.doi.org/10.1016/j.ijedudev.2015.05.003

Ai, C., \& Norton, E. C. (2003). Interaction terms in logit and probit models. Economics Letters, 80, 123-129. http://dx.doi.org/10.1016/s0165-1765(03)00032-6

Anderson, G. E., Whipple, A. D., \& Jimerson, S. R. (2003). Grade retention: Achievement and health outcomes. National Association for School Psychologists, 1-4. Retrieved from http://www.wrightslaw.com/info/fape.grade.retention.nasp.pdf

Angrist, J. D., \& Pischke, J. S. (2005). Mostly harmless econometrics: An empiricist's companion. Chapter 5: Parallel Worlds: Fixed effects, differences-in-differences, and panel data, 221-247. http://dx.doi.org/10.1007/s00362-009-0284-y

Antonakis, J., Bendahan, S., Jacquart, P., \& Lalive, R. (2010). On Making Causal Claims: A Review and $\begin{array}{llll}\text { Recommendations. The Leadership } & \text { Quarterly, }\end{array}$ http://dx.doi.org/10.1016/j.leaqua.2010.10.010

Ashenfelter, O., \& Card, D. (1985). Using the longitudinal structure of earnings to estimate the effects of training programs. Review of Economics and Statistics, 67, 648-660. http://dx.doi.org/10.2307/1924810

Athey, S., \& Imbens, G. W. (2006). Identification and inference in nonlinear difference-in-differences models. Econometrica, 74(2), 431-497. http://dx.doi.org/10.1111/j.1468-0262.2006.00668.x

Bertrand, M., Duflo, E., \& Mullainathan, S. (2004). How much should we trust differences-in-differences $\begin{array}{lllll}\text { estimates? The Quarterly Journal of Economics, 119(1), 249-275. } & \text {. }\end{array}$ http://dx.doi.org/10.1162/003355304772839588

Bius, M. (2010). Stata tip 87: Interpretation of interactions in non-linear models. The Stata Journal, 10(2), 305-308. Retrieved from http://www.stata-journal.com/sjpdf.html?articlenum=st0194

Bonneau, K. (2015). What is a dropout? Brief 3: North Carolina Education Research Data Center, Center for Child and Family Policy, pp. 1-4. Retrieved from https://www.purdue.edu/hhs/hdfs/fii/wp-content/uploads/2015/07/s_ncfis04c03.pdf

Brophy, J. (2006). Grade Repetition. International Academy for Education (IAE) and UNESCO International Institution for Educational Planning (IIEP). Education Policy Series 6, pp. 1-33. Retrieved from http://www.unesco.org/iiep/PDF/Edpol6.pdf

Bryson, A., Dorsett, R., \& Purdon, S. (2002). The Use of Propensity Score Matching in the Evaluation of Labour Market Policies. Working Paper No. 4, Department for Work and Pensions, pp. 1-52. Retrieved from http://eprints.lse.ac.uk/4993/1/The_use_of_propensity_score_matching_in_the_evaluation_of_active_labou r_market_policies.pdf

Byamugisha, A. (2010). Examining the Effects of School Environment Factors on Pupil's Learning Achievement in Uganda Primary Schools. African Education Research Journal, 1, 110-133. Retrieved from https://docs.google.com/file/d/0BxjnVLC402PwajdaT0xZbTZUNHVsN1BzLVRGaU1Bdw/edit

Caliendo, M., \& Kopeinig, S. (2005). Some practical guidance for the implementation of propensity score matching. IZA Discussion Paper No. 1588, pp. 1-29. Retrieved from http://ftp.iza.org/dp1588.pdf 
Card, D., \& Krueger, A. (1994). Minimum Wages and Employment: A Case Study of the Fast-Food Industry in New Jersey and Pennsylvania. The American Economic Review, 84(4), 777-793. http://dx.doi.org/10.3386/w4509

Chapman, C. (2011). Trends in High School Dropout and Completion Rates in the United States: 1972-2009. National Center for Education Statistics 2012-006, pp. 1-108. Retrieved from https://nces.ed.gov/pubs2012/2012006.pdf

Chohan, B. I., \& Qadir, S. A. (2011). Automatic Promotion Policy at Primary Level and MDG-2. Journal of Research and Reflections in Education, 5(1), 1-20. Retrieved from https://www.researchgate.net/profile/Bushra_Iqbal_Chohan/publication/216035878_Automatic_Promotion _Policy_at_Primary_Level_and_MDG-2/links/0deec51750ab4a510b000000.pdf

Doll, J. J., Eslami, Z., \& Walters, L. (2013). Understanding why students drop out of high school, according to their own reports: Are they pushed or pulled, or do they fall out? A comparative analysis of seven nationally representative studies. SAGE Open, 3(4), 1-15. http://dx.doi.org/10.1177/2158244013503834

Eide, E. R., \& Showalter, M. H. (2001). The Effect of Grade Retention on Educational and Labor Market Outcomes. Economics of Education Review, 20, 563-576. http://dx.doi.org/10.1016/s0272-7757(00)00041-8

Froman, T., \& Brown, S. (2008). Third-grade retention: A four-year follow-up. Research Brief-Research Services, pp. 1-5. Retrieved from http://files.eric.ed.gov/fulltext/ED538712.pdf

Glick, P., \& Sahn, D. E. (2010). Early Academic Performance, Grade Repetition, and School Attainment in Senegal: A Panel Data Analysis. The World Bank Economic Review, pp. 1-28. Retrieved from https://openknowledge.worldbank.org/bitstream/handle/10986/4516/wber_24_1_93.pdf?sequence=1

Gomes-Neto, J. B., \& Hanushek, E. A. (1994). The Causes and Effects of Grade Repetition, Chapter 15: Opportunity Foregone: Education in Brazil. Inter-America Development Bank, pp. 117-148. http://dx.doi.org/10.1086/452138

Hastings, J. (2004). Vertical Relationships and Competition in Retail Gasoline Markets: Empirical Evidence from Contract Changes in Southern California. The American Economic Review, 94(1), 317-328. http://dx.doi.org/10.1257/000282804322970823

Hirakawa, Y., \& No, F. (2012). Identifying causes of dropout through longitudinal quantitative analysis in rural Cambodian basic schools. Journal of International Development and Cooperation, 19(1), 25-39. Retrieved from http://ir.lib.hiroshima-u.ac.jp/files/public/3/33828/20141016195805437401/JIDC_19-1_25.pdf

Hoetker, G. (2007). The use of logit and probit models in strategic management research: Critical Issues. Strategic Management Journal, 28, 331-343. Retrieved from http://hoetker.faculty.asu.edu/resources/research/Hoetker_2007_SMJ.pdf

Hoff, N., Olsen, A., \& Peterson, R. L. (2015). Dropout screening and early warning. Topic Brief, University of Nebraska-Lincoln, $\quad$ pp. $1-15 . \quad$ Retrieved from https://k12engagement.unl.edu/DropoutScreening\&EarlyWarning3-27-15.pdf

Imbens, G. W., \& Wooldridge, J. M. (2007). Difference-in-differences estimation. National Bureau of Economic Research (NBER), Summer Lecture Notes 10, pp. 1-19. Retrieved from http://www.nber.org/WNE/lect_10_diffindiffs.pdf

Jimerson, S. R., \& Ferguson, P. (2007). A longitudinal study of grade retention: Academic and behavioral outcomes of retained students through adolescence. School Psychology Quarterly, 22(3), 314-339. http://dx.doi.org/10.1037/1045-3830.22.3.314

Jimerson, S. R., Carlson, E., Rotert, M., Egeland, B., \& Sroufe, L. A. (1997). A prospective, longitudinal study of the correlates and consequences of early grade retention. Journal of School Psychology, 35(1), 3-25. http://dx.doi.org/10.1016/s0022-4405(96)00033-7

Kasirye, I. (2009). Determinants of learning achievement (Grade 6) in Uganda. Economic Policy Research Centre (EPRC), Makerere University, Kampala -Uganda, pp. 1-39. Retrieved from http://www.csae.ox.ac.uk/conferences/2009-edia/papers/325-kasirye.pdf

King, E. M., Orazem P. F., \& Paterno E. M. (1999). Promotion with and without learning: Effects on student dropout. The World Bank Development Research Group. Working Paper Series on Impact Evaluation of Education Reforms Paper No. 18, pp. 1-28. http://dx.doi.org/10.1596/1813-9450-4722 
Koppensteiner, M. F. (2014). Automatic grade promotion and student performance: Evidence from Brazil. Journal of Development Economics, 107, 277-290. http://dx.doi.org/10.1016/j.jdeveco.2013.12.007

Lehr, C. A., Johnson, D. R., Bremer, C. D., Cosio, A., \& Thompson, M. (2004). Increasing Rates of School Completion: Moving From Policy and Research to Practice. A Manual for Policymakers, Administrators, and Educators. The College of Education and Human Development, University of Minnesota. pp. 1-67. Retrieved from http://www.ncset.org/publications/essentialtools/dropout/dropout.pdf

Lloyd, C. B., Mete, C., \& Sathar, Z. A. (2005). The Effect of Gender Differences in Primary School Access, Type, and Quality on the Decision to Enroll in Rural Pakistan. Economic Development and Cultural Change, 53(3), 685-710. Retrieved from http://www.jstor.org/stable/10.1086/427042

Manacorda, M. (2006). Grade failure, dropout and subsequent school outcomes: Quasi-experimental evidence from Uruguayan Administrative Data. London School of Economics, pp. 1-73. Retrieved from http://cep.lse.ac.uk/seminarpapers/13-12-06-MAN.pdf

Mehrotra, S. (1998). Education for All: Policy Lessons from High-Achieving Countries. International Review of Education, 44(5/6), 461-484. http://dx.doi.org/10.1023/a:1003433029696

Ministry of Education, Science, Technology and Sports, Uganda. (2014). The education and sports sector annual $\begin{array}{lllll}\text { performance } & \text { report. } & \text { pp. } & 171-177 . & \text { Retrieved }\end{array}$ http://www.education.go.ug/files/downloads/ESSAPR\%202013_14\%20(1).pdf

Morgan, S. L., \& Winship, C. (2007). Repeated observations and the estimation of causal effects: Counterfactuals and causal inference: Methods and principles for social research (pp. 243-274). New York: Cambridge University Press.

Murnane, R. J., \& Willet, J. B. (2011). Dealing with bias in treatment effects estimated from non-experimental data: Methods matter: Improving causal inference in educational and social science research (pp. 286-331). New York: Oxford University Press.

Muvawala. (2012). Determinants of learning outcomes for primary education: A case of Uganda. The African Statistical Journal, $\quad 15, \quad 42-54 . \quad$ Retrieved from http://www.afdb.org/fileadmin/uploads/afdb/Documents/Publications/ASJ15\%20Section3\%20Eng.pdf

Myung, H., Hughes, J. N., Kwok, O., Puckett, S., \& Cerda, C. A. (2013). Effect of Retention in Elementary Grades on Transition to Middle School. Journal of School Psychology, 51(3), 349-365. http://dx.doi.org/10.1016/j.jsp.2013.01.004

Nannyonjo, H. (2007). Education inputs in Uganda: An analysis of factors influencing learning achievements in grade six. African Region Human Development Series Number 98, World Bank, pp. 1-89. http://dx.doi.org/10.1596/978-0-8213-7056-8

Ndaruhutse, S. (2008). Grade repetition in primary schools in Sub-Saharan Africa: an evidence base for change. Center for British Teachers Education Trust, pp. 1-79. Retrieved from http://www.consultasrodac.sep.gob.mx/cartilla/pdf/Grade\%20Repetition_FINAL_8FEB08.pdf

Nishimura, M., \& Ogawa, K., (2009). Universal Primary Education Policy and Quality of Education in Sub-Saharan Africa: A Comparative Analysis of Malawi, Ghana, Kenya and Uganda and Policy Recommendations. Journal of International Cooperation in Education, 12(1), 143-158. Retrieved from http://home.hiroshima-u.ac.jp/cice/wp-content/uploads/2014/03/12-1-10.pdf

Ogawa, K., Nishimura, M., \& Byamugisha, A. (2011). Universal Primary Education Policy and Quality of Education in Sub-Saharan Africa: The Case Study of Soroti and Kabale Districts in Uganda. African Education Research Journal, Japan, 1, 60-66. Retrieved from Kobe University Library (Hard Copy)

Okumu, I. M., Nakajjo, A., \& Isoke, D. (2008). Socioeconomic determinants of primary school dropout: the logistic model analysis. Economic Policy Research Center, Makerere University and Munich Personal RePEc Archive, pp. 1-25. Retrieved from http://mpra.ub.uni-muenchen.de/7851/

Okurut, J. M. (2015). Examining the effect of automatic promotion on students' learning achievements in Uganda's primary education. World Journal of Education, 5(5), 85-100. http://dx.doi.org/10.5430/wje.v5n5p85

Puhani, P. A. (2012). The treatment effect, the cross difference, and the interaction term in nonlinear

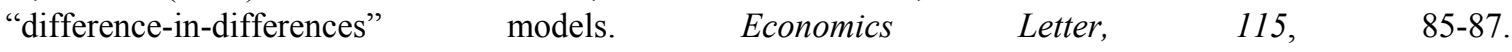
http://dx.doi.org/10.1016/j.econlet.2011.11.025 
Sabates, R., Akyeampong, K., Westbrook, J., \& Hunt, F. (2010). School Dropout: Patterns, causes changes and policies. Background paper for the Education For All Global Monitoring Report (2011). The hidden crises: Armed conflict and education, pp. 1-25. Retrieved from http://unesdoc.unesco.org/images/0019/001907/190771e.pdf

Sainani, K. L. (2012). Propensity Scores: Uses and limitations. The American Academy of Physical Medicine and Rehabilitation, 4, 693-697. Retrieved from http://www.pmrjournal.org/article/S1934-1482(12)00346-2/pdf

Sawada, Y., \& Lokshin, M. (2009). Obstacles to school progression in rural Pakistan: An analysis of gender and sibling rivalry using field survey data. Journal of Development Economics, 88, 335-347. http://dx.doi.org/10.1016/j.jdeveco.2008.03.002

Steiner, K. (1986). Grade retention and promotion. ERIC Clearinghouse on Elementary and Early Childhood Education, ERIC Digest, pp. 1-3. Retrieved from http://files.eric.ed.gov/fulltext/ED267899.pdf

Stuart, E. A., Huskamp, H. A., \& Duckworth, K. (2014). Using propensity scores in difference-in-differences models to estimate the effects of a policy change. Health Services Outcomes Research Method, 14, 166-182. http://dx.doi.org/10.1007/s10742-014-0123-z

Tamusuza, A. (2011). Leaving School Early: The quest for Universal Primary Education in Uganda. The African Statistical Journal, 13, 110-151. Retrieved from http://www.afdb.org/fileadmin/uploads/afdb/Documents/Publications/Leaving\%20School\%20Early\%20The \%20Quest.pdf

Taye, D. (2003). Automatic Promotion Practices in the First-Cycle of Primary Schools in West Gojjam Zone. Addis Ababa University, School of Graduate Studies, pp. 1-123. Retrieved from http://www.academia.edu/2446791/AUTOMATIC_PROMOTION_PRACTICES_IN_THE_FIRST-CYCL E_OF_PRIMARY_SCHOOLS_IN_WEST_GOJJAM_ZONE

Thurlow, M. L., Sinclair, M. F., \& Johnson, D. R. (2002). Students with disabilities who drop out of school: Implications for policy and practice. Issue Brief, 1(2). Minneapolis, MN: University of Minnesota, Institute on Community Integration, National Center on Secondary Education and Transition, pp. 1-10. Retrieved from http://files.eric.ed.gov/fulltext/ED468582.pdf

Vaidheesh, S. (2013). Delivering on the Promise of Access to Education: Improving Primary School Completion Rates in Brazil. Harvard Graduate School of Education, pp. 1-29. Retrieved from http://isites.harvard.edu/fs/docs/icb.topic1203150.files/Panel\%202\%20-\%20Finishing\%20the\%20Treatmen t/SunandaVaidheesh_Brazil_PrimarySchoolCompletion.pdf

Westbury, M. (1994). The Effect of Elementary Grade Retention on Subsequent School Achievement and Ability. Canadian Journal of Education, 19(3), 241-250. http://dx.doi.org/10.2307/1495130

Williams, R. (2012). Using margins command to estimate and interpret adjusted predictions and marginal effects. The Stata Journal, 12(2), 308-331. Retrieved from https://www3.nd.edu/ rwilliam/stats/Margins01.pdf

Zarif, T., Haider, K., Ahmed, A., \& Bano, F. (2014). Probing Reasons of High Student Dropout Rate in Grade 5-6 at Public Schools of District Thatta, Sindh-Pakistan. Asian Journal of Social Sciences \& Humanities, 3(1), 158-169. Retrieved from http://www.ajssh.leena-luna.co.jp/AJSSHPDFs/Vol.3(1)/AJSSH2014(3.1-15).pdf

Zelner, B. A. (2009). Using simulation to interpret results from logit, probit and other nonlinear models. Strategic Management Journal, 30, 1335-1348. http://dx.doi.org/10.1002/smj.783

\section{Note.}

Note 1. Equation (2) and Equation (3) and their respective explanations were adopted from Stuart et al. (2014): "Using Propensity Score in Difference in Differences Models." 


\section{Appendix}

Table 1. Mean characteristics of the Control and Treated groups at P.3, during 2004 and 2010, across recorded covariates

\begin{tabular}{|c|c|c|c|c|c|c|c|c|c|c|c|c|}
\hline \multirow[t]{3}{*}{$\mathrm{N}=30053$} & \multicolumn{6}{|c|}{ Before (2004) } & \multicolumn{6}{|c|}{ After (2010) } \\
\hline & \multicolumn{2}{|c|}{ Control } & \multicolumn{2}{|c|}{ Treated } & \multirow[b]{2}{*}{ P-Value } & \multirow[b]{2}{*}{ Norm-diff } & \multicolumn{2}{|c|}{ Control } & \multicolumn{2}{|c|}{ Treated } & \multirow[b]{2}{*}{ P-Value } & \multirow[b]{2}{*}{ Norm-diff } \\
\hline & Mean & $\mathrm{SD}$ & Mean & $\mathrm{SD}$ & & & Mean & SD & Mean & $\mathrm{SD}$ & & \\
\hline \multicolumn{13}{|l|}{ School Factors } \\
\hline Guidance and Counselling & 0.388 & 0.487 & 0.369 & 0.443 & 0.000 & 0.029 & 0.356 & 0.479 & 0.286 & 0.452 & 0.000 & 0.105 \\
\hline Distance to Sec. School & 4.079 & 2.957 & 5.595 & 13.144 & 0.006 & -0.113 & 6.223 & 19.160 & 5.341 & 11.820 & 0.007 & 0.039 \\
\hline Distance to Market & 2.546 & 4.500 & 2.121 & 3.962 & 0.014 & 0.071 & 1.894 & 4.616 & 2.187 & 3.938 & 0.005 & -0.048 \\
\hline Reading Textbooks & 0.930 & 0.253 & 0.924 & 0.263 & 0.599 & 0.016 & 0.925 & 0.262 & 0.921 & 0.268 & 0.581 & 0.011 \\
\hline Mathematics Textbooks & 0.895 & 0.306 & 0.917 & 0.275 & 0.068 & -0.053 & 0.926 & 0.260 & 0.910 & 0.284 & 0.033 & 0.042 \\
\hline Student Writing Surface & 0.998 & 0.042 & 0.974 & 0.156 & 0.000 & 0.149 & 0.970 & 0.168 & 0.973 & 0.161 & 0.526 & -0.013 \\
\hline Student Sitting Surface & 0.976 & 0.150 & 0.962 & 0.188 & 0.086 & 0.058 & 0.968 & 0.175 & 0.968 & 0.173 & 0.853 & 0.000 \\
\hline School Feeding Frogram & 0.205 & 0.072 & 0.202 & 0.402 & 0.000 & 0.007 & 0.133 & 0.340 & 0.181 & 0.385 & 0.000 & -0.093 \\
\hline Extra Lessons & 0.506 & 0.491 & 0.521 & 0.499 & 0.000 & -0.021 & 0.570 & 0.495 & 0.521 & 0.499 & 0.000 & 0.070 \\
\hline Teachers Meet Parents & 0.898 & 0.301 & 0.917 & 0.274 & 0.120 & -0.047 & 0.922 & 0.267 & 0.916 & 0.276 & 0.433 & 0.015 \\
\hline \multicolumn{13}{|l|}{ Teacher Factors } \\
\hline Teacher Education & 3.310 & 1.107 & 3.307 & 1.011 & 0.946 & 0.002 & 3.182 & 0.981 & 3.315 & 1.006 & 0.000 & -0.095 \\
\hline Teacher Experierce & 9.618 & 5.684 & 9.624 & 6.529 & 0.465 & -0.001 & 9.675 & 5.985 & 9.558 & 6.428 & 0.491 & 0.013 \\
\hline Teacher Comes Late & 0.982 & 0.182 & 0.957 & 0.201 & 0.004 & 0.092 & 0.979 & 0.143 & 0.961 & 0.192 & 0.000 & 0.075 \\
\hline Teacher Absenteeism & 0.941 & 0.234 & 0.923 & 0.265 & 0.123 & 0.051 & 0.977 & 0.147 & 0.922 & 0.267 & 0.000 & 0.180 \\
\hline Teacher Skips Classes & 0.828 & 0.377 & 0.783 & 0.443 & 0.000 & 0.077 & 0.808 & 0.393 & 0.728 & 0.441 & 0.000 & 0.135 \\
\hline \multicolumn{13}{|l|}{ Student Factors } \\
\hline Gender & 0.528 & 0.499 & 0.511 & 0.499 & 0.438 & 0.024 & 0.532 & 0.499 & 0.511 & 0.499 & 0.099 & 0.030 \\
\hline Age in Years & 9.421 & 1.476 & 10.62 & 1.564 & 0.000 & -0.559 & 9.739 & 1.558 & 10.64 & 1.567 & 0.000 & -0.410 \\
\hline Student Repeated & 0.384 & 0.486 & 0.534 & 0.498 & 0.000 & -0.216 & 0.540 & 0.498 & 0.528 & 0.499 & 0.393 & 0.017 \\
\hline Student receive homework & 0.929 & 0.256 & 0.937 & 0.242 & 0.451 & -0.023 & 0.938 & 0.239 & 0.929 & 0.256 & 0.162 & 0.026 \\
\hline Student receive corrections & 0.925 & 0.262 & 0.937 & 0.242 & 0.272 & -0.034 & 0.938 & 0.239 & 0.929 & 0.256 & 0.162 & 0.026 \\
\hline Student comes late & 0.955 & 0.206 & 0.988 & 0.105 & 0.000 & -0.143 & 0.986 & 0.113 & 0.983 & 0.127 & 0.278 & 0.018 \\
\hline Student Absenteeism & 1.000 & 0.000 & 0.995 & 0.061 & 0.128 & 0.082 & 1.000 & 0.000 & 0.995 & 0.063 & 0.009 & 0.079 \\
\hline Student Skips Classes & 0.895 & 0.306 & 0.78 & 0.413 & 0.000 & 0.222 & 0.884 & 0.319 & 0.798 & 0.401 & 0.000 & 0.168 \\
\hline Student Attended Nursery & 0.430 & 0.495 & 0.486 & 0.499 & 0.010 & -0.080 & 0.587 & 0.492 & 0.483 & 0.499 & 0.000 & 0.148 \\
\hline Student speaks English & 0.863 & 0.343 & 0.85 & 0.355 & 0.456 & 0.024 & 0.822 & 0.382 & 0.849 & 0.358 & 0.005 & -0.052 \\
\hline \multicolumn{13}{|l|}{$\begin{array}{l}\text { Household Factors } \\
\text { loll }\end{array}$} \\
\hline Mothers Education & 0.835 & 0.371 & 0.802 & 0.397 & 0.061 & 0.061 & 0.831 & 0.374 & 0.797 & 0.401 & 0.001 & 0.062 \\
\hline Fathers Education & 0.877 & 0.327 & 0.879 & 0.326 & 0.923 & -0.004 & 0.896 & 0.304 & 0.875 & 0.329 & 0.018 & 0.047 \\
\hline Children in a Household & 1.230 & 1.127 & 1.272 & 1.133 & 0.400 & -0.026 & 1.341 & 1.141 & 1.493 & 0.169 & 0.000 & -0.132 \\
\hline Source of Light at Night & 0.315 & 0.465 & 0.373 & 0.483 & 0.005 & -0.087 & 0.247 & 0.431 & 0.095 & 0.294 & 0.000 & 0.291 \\
\hline Household owns a Radio & 0.712 & 0.452 & 0.725 & 0.446 & 0.509 & -0.020 & 0.667 & 0.471 & 0.572 & 0.494 & 0.000 & 0.139 \\
\hline Household owns a TV & 0.297 & 0.457 & 0.347 & 0.476 & 0.017 & -0.076 & 0.230 & 0.421 & 0.095 & 0.294 & 0.000 & 0.263 \\
\hline Expenditure on Education & 40.806 & 141.11 & 41.448 & 186.49 & 0.936 & -0.003 & 34.363 & 145.72 & 36.89 & 169.77 & 0.569 & -0.011 \\
\hline Distance to Primary School & 4.015 & 3.142 & 3.819 & 2.935 & 0.125 & 0.046 & 3.793 & 2.972 & 3.776 & 2.960 & 0.833 & 0.004 \\
\hline
\end{tabular}

Source: Created by Author using NAPE (2004 and 2010) and UNHS (2004 and 2010).

Table 2. Mean characteristics of the Control and Treated groups at P.6, during 2004 and 2010, across recorded covariates

\begin{tabular}{|c|c|c|c|c|c|c|c|c|c|c|c|c|}
\hline \multirow[t]{3}{*}{$\mathrm{N}=26720$} & \multicolumn{6}{|c|}{ Before (2004) } & \multicolumn{6}{|c|}{ After (2010) } \\
\hline & \multicolumn{2}{|c|}{ Control } & \multicolumn{2}{|c|}{ Treated } & \multirow[b]{2}{*}{ P-Value } & \multirow[b]{2}{*}{ Norm-diff } & \multicolumn{2}{|c|}{ Control } & \multicolumn{2}{|c|}{$\begin{array}{l}\text { Treated } \\
\text { SD }\end{array}$} & \multirow[b]{2}{*}{ P-Value } & \multirow[b]{2}{*}{ Ncrm-diff } \\
\hline & Mean & $\mathrm{SD}$ & Mean & SD & & & Mean & SD & Mean & $\mathrm{SD}$ & & \\
\hline \multicolumn{13}{|l|}{ School Factors } \\
\hline Guidance and Counselling & 0.286 & 0.452 & 0.285 & 0.451 & 0.956 & 0.002 & 0.305 & 0.46 & 0.28 & 0.449 & 0.000 & 0.039 \\
\hline Distance to Sec. School & 5.943 & 16.19 & 5.836 & 15.37 & 0.813 & 0.005 & 5.731 & 14.16 & 5.348 & 12.08 & 0.037 & 0.021 \\
\hline Distance to Market & 2.271 & 4.415 & 2.283 & 4.392 & 0.925 & -0.002 & 2.153 & 4.024 & 2.116 & 3.745 & 0.508 & 0.007 \\
\hline Reading Textbooks & 0.903 & 0.294 & 0.931 & 0.253 & 0.000 & -0.072 & 0.916 & 0.276 & 0.925 & 0.263 & 0.025 & -0.024 \\
\hline Mathematics Textbooks & 0.903 & 0.295 & 0.916 & 0.276 & 0.114 & -0.032 & 0.912 & 0.283 & 0.912 & 0.283 & 0.967 & 0.000 \\
\hline Student Writing Surface & 0.978 & 0.144 & 0.969 & 0.17 & 0.065 & 0.040 & 0.972 & 0.162 & 0.973 & 0.161 & 0.953 & -0.004 \\
\hline Student Sitting Surface & 0.975 & 0.153 & 0.964 & 0.184 & 0.030 & 0.046 & 0.969 & 0.172 & 0.968 & 0.174 & 0.764 & 0.004 \\
\hline School Feeding Program & 0.174 & 0.379 & 0.183 & 0.386 & 0.450 & -0.017 & 0.18 & 0.384 & 0.178 & 0.382 & 0.694 & 0.004 \\
\hline Extra Lessons & 0.502 & 0.5 & 0.531 & 0.499 & 0.043 & -0.041 & 0.531 & 0.499 & 0.516 & 0.499 & 0.032 & 0.021 \\
\hline Teachers Meet Parents & 0.915 & 0.278 & 0.916 & 0.277 & 0.910 & -0.003 & 0.92 & 0.270 & 0.915 & 0.278 & 0.211 & 0.013 \\
\hline \multicolumn{13}{|l|}{ Teacher Factors } \\
\hline Teacher Education & 3.330 & 0.978 & 3.320 & 1.011 & 0.710 & 0.007 & 3.328 & 1.000 & 3.294 & 1.011 & 0.018 & 0.024 \\
\hline Teacher Experience & 9.416 & 6.304 & 9.47 & 6.414 & 0.771 & -0.006 & 9.361 & 6.329 & 9.656 & 6.469 & 0.001 & -0.033 \\
\hline Teacher Comes Late & 0.967 & 0.177 & 0.959 & 0.197 & 0.151 & 0.030 & 0.966 & 0.179 & 0.960 & 0.195 & 0.015 & 0.023 \\
\hline Teacher Absenteeism & 0.921 & 0.268 & 0.925 & 0.261 & 0.594 & -0.011 & 0.927 & 0.259 & 0.924 & 0.264 & 0.427 & 0.008 \\
\hline Teacher Skips Classes & 0.732 & 0.443 & 0.734 & 0.441 & 0.874 & -0.003 & 0.738 & 0.439 & 0.73 & 0.443 & 0.199 & 0.013 \\
\hline \multicolumn{13}{|l|}{ Student Factors } \\
\hline Gender & 0.800 & 0.400 & 0.771 & 0.419 & 0.018 & 0.050 & 0.512 & 0.499 & 0.508 & 0.499 & 0.520 & 0.006 \\
\hline Age in Years & 13.53 & 1.477 & 13.76 & 1.390 & 0.000 & -0.113 & 13.65 & 1.535 & 13.86 & 1.424 & 0.000 & -0.100 \\
\hline Student Repeated & 0.524 & 0.499 & 0.531 & 0.499 & 0.635 & -0.010 & 0.530 & 0.499 & 0.529 & 0.499 & 0.889 & 0.001 \\
\hline Student receive homework & 0.916 & 0.277 & 0.937 & 0.241 & 0.003 & -0.057 & 0.928 & 0.258 & 0.93 & 0.253 & 0.437 & -0.006 \\
\hline Student receive corrections & 0.917 & 0.275 & 0.937 & 0.242 & 0.007 & -0.055 & 0.927 & 0.258 & 0.93 & 0.253 & 0.404 & -0.008 \\
\hline Student comes late & 0.983 & 0.126 & 0.982 & 0.129 & 0.847 & 0.006 & 0.983 & 0.128 & 0.983 & 0.127 & 0.965 & 0.000 \\
\hline Student Absenteeism & 0.998 & 0.033 & 0.996 & 0.062 & 0.074 & 0.028 & 0.996 & 0.059 & 0.995 & 0.065 & 0.342 & 0.011 \\
\hline Student Skips Classes & 0.784 & 0.411 & 0.809 & 0.392 & 0.031 & -0.044 & 0.799 & 0.400 & 0.803 & 0.397 & 0.527 & -0.007 \\
\hline Student Attended Nursery & 0.480 & 0.499 & 0.481 & 0.499 & 0.955 & -0.001 & 0.488 & 0.499 & 0.485 & 0.499 & 0.637 & 0.004 \\
\hline Student speaks English & 0.837 & 0.368 & 0.845 & 0.361 & 0.442 & -0.016 & 0.852 & 0.354 & 0.850 & 0.357 & 0.676 & 0.004 \\
\hline \multicolumn{13}{|l|}{ Household Factors } \\
\hline Mothers Education & 0.802 & 0.398 & 0.799 & 0.400 & 0.797 & 0.005 & 0.801 & 0.398 & 0.799 & 0.400 & 0.691 & 0.004 \\
\hline Fathers Education & 0.878 & 0.326 & 0.876 & 0.329 & 0.789 & 0.004 & 0.875 & 0.33 & 0.878 & 0.327 & 0.498 & -0.006 \\
\hline Children in a Household & 1.421 & 1.145 & 1.374 & 1.143 & 0.157 & 0.029 & 1.386 & 1.156 & 1.429 & 1.172 & 0.009 & -0.026 \\
\hline Source of Light at Night & 0.214 & 0.41 & 0.216 & 0.411 & 0.829 & -0.003 & 0.207 & 0.405 & 0.193 & 0.395 & 0.012 & 0.025 \\
\hline Household owns a Radio & 0.676 & 0.467 & 0.696 & 0.459 & 0.143 & -0.031 & 0.672 & 0.469 & 0.682 & 0.465 & 0.121 & -0.015 \\
\hline Household owns a TV & 0.201 & 0.4 & 0.21 & 0.407 & 0.418 & -0.016 & 0.196 & 0.397 & 0.185 & 0.388 & 0.066 & 0.020 \\
\hline Expenditure on Education & 42.4 & 223.58 & 42.32 & 198.59 & 0.989 & 0.0003 & 37.49 & 172.65 & 38.04 & 168.66 & 0.822 & -0.002 \\
\hline Distance to Primary School & 3.78 & 2.917 & 3.839 & 2.96 & 0.495 & -0.014 & 3.841 & 2.935 & 3.822 & 2.951 & 0.649 & 0.005 \\
\hline
\end{tabular}

Source: Created by Author using NAPE (2004 \& 2010) and UNHS (2004 \& 2010). 


\section{Copyrights}

Copyright for this article is retained by the author(s), with first publication rights granted to the journal.

This is an open-access article distributed under the terms and conditions of the Creative Commons Attribution license (http://creativecommons.org/licenses/by/4.0/). 